\title{
Mollusk communities of the central Congo River shaped by combined effects of barriers, environmental gradients, and species dispersal
}

\author{
Oscar WEMBO NDEO $, 1,2,3 *$ Torsten HAUFFE, ${ }^{2}$ Diana DELICADO,${ }^{2}$ Alidor KANKONDA BUSANGA, ${ }^{1}$ \\ Christian ALBRECHT ${ }^{2,3}$
}

${ }^{1}$ Department of Hydrobiology and Aquaculture, University of Kisangani, BP 2012, Kisangani, D. R. Congo; ${ }^{2}$ Department of Animal Ecology and Systematics, Justus Liebig University Giessen, Heinrich-Buff-Ring 26-32 (IFZ), D-35392 Giessen, Germany; ${ }^{3}$ Department of Biology, Faculty of Science Mbarara University of Science and Technology, P. O. Box 1410, Mbarara, Uganda

*Corresponding author: wemboscar@googlemail.com

\begin{abstract}
Rapids, falls, and cascades might act as barriers for freshwater species, determining the species community up- and downstream of barriers. However, they affect community composition not only by acting as barriers but also by their influence on environmental gradients. Moreover, the directional dispersal of species along the watercourse might determine community composition. A suitable system to study these differential effects is the Congo River, the world's second largest river by discharge. The small 'Upper Congo Rapids' ecoregion features several rapids known as barrier for fish. The Wagenia Cataract at the town of Kisangani constitutes the strongest drop of the Congo River and several studies have emphasized its role as barrier for fish distribution. Alternative explanations for this pattern, however, are rarely evaluated. Though mollusks represent a vital component of the macrozoobenthos, with distribution patterns and underlying drivers often distinct from that of fishes, virtually no field surveys of the Congo River have been reported for decades. We collected and determined mollusks of 51 stations, recorded environmental conditions, and generated proxies for directional species dispersal and an indirect barrier effect. Those variables were subjected to distance-based redundancy analyses and variation partitioning in order to test whether the mollusk community compositions are better explained by an individual or combined influence of the direct and indirect effect of the cataract barrier, environmental conditions, and downstreamdirected dispersal. Our survey showed an exclusive upstream/downstream distribution for just four out of the 19 species, suggesting a limited barrier effect. We revealed no direct influence of the barrier itself on community composition but of substrate type. However, we found an indirect effect of the barrier through replacing spatially structured communities upstream of the cataract with more uniform ones downstream. Downstream-directed dispersal explained the highest fraction of variation in mollusk communities. Thus, environmental factors, the indirect cataract effect, and downstream-directed spatial proxies model mollusk community composition in concert. These results support previous studies showing a multi-factorial imprint on communities. However, a large fraction of variation community composition remained unexplained, potentially due to flood plain dynamics that (re-)shape mollusk communities constantly and a high temporal turnover, evidenced by the comparison with historical surveys. This is likely caused by the growth of Kisangani and resulting human activities. A monitoring system could allow better assessments of these impacts on communities and the conservation status of endemic species in the Wagenia Cataract.
\end{abstract}

Key words: Wagenia Cataract; Stanley Falls; biotic homogenization; Eigenvector maps; conservation.

Received: October 2016. Accepted: April 2017.

\section{INTRODUCTION}

The interchange of organisms among areas is largely determined by geographical and ecological connectivity (Tischendorf and Fahrig, 2000; Dias et al., 2014; Heino et al., 2015), which acts through several factors that promote or impede species dispersal. In the particular case of freshwater systems, biogeographic barriers are one of the most influential factors for faunal composition (Tisseuil et al., 2013), acting at continental, regional, and local scale (Rahel, 2007). Within river basins, rapids, falls, and cascades might act as strong or partial local barriers for species dispersal and consequently shape the species community up- and downstream (Torrente-Vilara et al., 2011).
Our study is focused on the effect of such local barriers on freshwater mollusk communities.

Rapids, falls, or cascades may affect community composition not only by acting as dispersal barriers but also by their influence on environmental conditions. Due to the currents, for instance, water is enriched in oxygen and the environmental gradient along the river continuum may be punctuated by these water masses. Rapids, falls, and cascades themselves are particularly important habitats, because they are composed of specific microhabitats typically occupied by habitat specialists adapted to high water speed and oxygen levels. Consequently, the occurrence and distribution of the riverine faunas may vary between up- and downstream sections, which are influenced 
by distinct shifts in water parameters such as current speed, temperature, season, substratum, depth, vegetation, dissolved substances, and other parameters (Allan and Castillo, 2007; Hynes, 2001).

Mollusks represent a vital component of the macrozoobenthic communities in rivers. In particular, diversity in vegetation and substrates has been found to account for differences in riverine mollusk communities (Maqboul et al., 2014; Reckendorfer et al., 2006). In addition, climate conditions and anthropogenic influences play also an important role in shaping modern distribution patterns of freshwater mollusks (Barkia et al., 2014; Van Bocxlaer et al., 2015; Beracko et al., 2016).

Besides barriers and environmental factors, the directional dispersal of species might also determine mollusk community composition. High dispersal rates eventually homogenize species communities and downstream-directed dispersal is a major process influencing communities of passively dispersing macroinvertebrates (Liu et al., 2013). In contrast, most mollusks attach to substrate and the potential rheotactic movement (i.e., active against the water flow) of adults theoretically counteracts downstream drift
(Kappes and Haase, 2012). However, strong water flow, irrespectively of the pure barrier effect of rapids and cataracts, might overrule the rheotactic movement of organisms.

A suitable system to study the differential effect of dispersal barriers, local environmental factors, and directional dispersal on freshwater mollusk communities is the Congo River (Fig. 1). Between Ubundu and Kisangani, the Congo crosses a section with rapids, cataracts, and falls (Runge, 2008). The Boyoma Falls, formerly known as Stanley Falls, consist of seven cataracts, all of them less than $5 \mathrm{~m}$ high, extending over dozens of kilometers upstream from Kisangani (Beadle, 1981). One of the most significant of all cataracts of the Boyoma Falls is the Wagenia Cataract at Kisangani (Fig. 1c).

Several investigations have emphasized the role of the Boyoma Falls as geographical barrier for fish (Poll, 1963; Decru et al., 2016). Some fishes are found either up- or downstream of the Wagenia Cataract, but only in rare cases in both. Because of observations like this, the 'Upper Congo Rapids' were classified as a small but distinct area within a global delineation of freshwater ecoregions (Fig. 1 a,b; Abell et al., 2008). It constitutes the
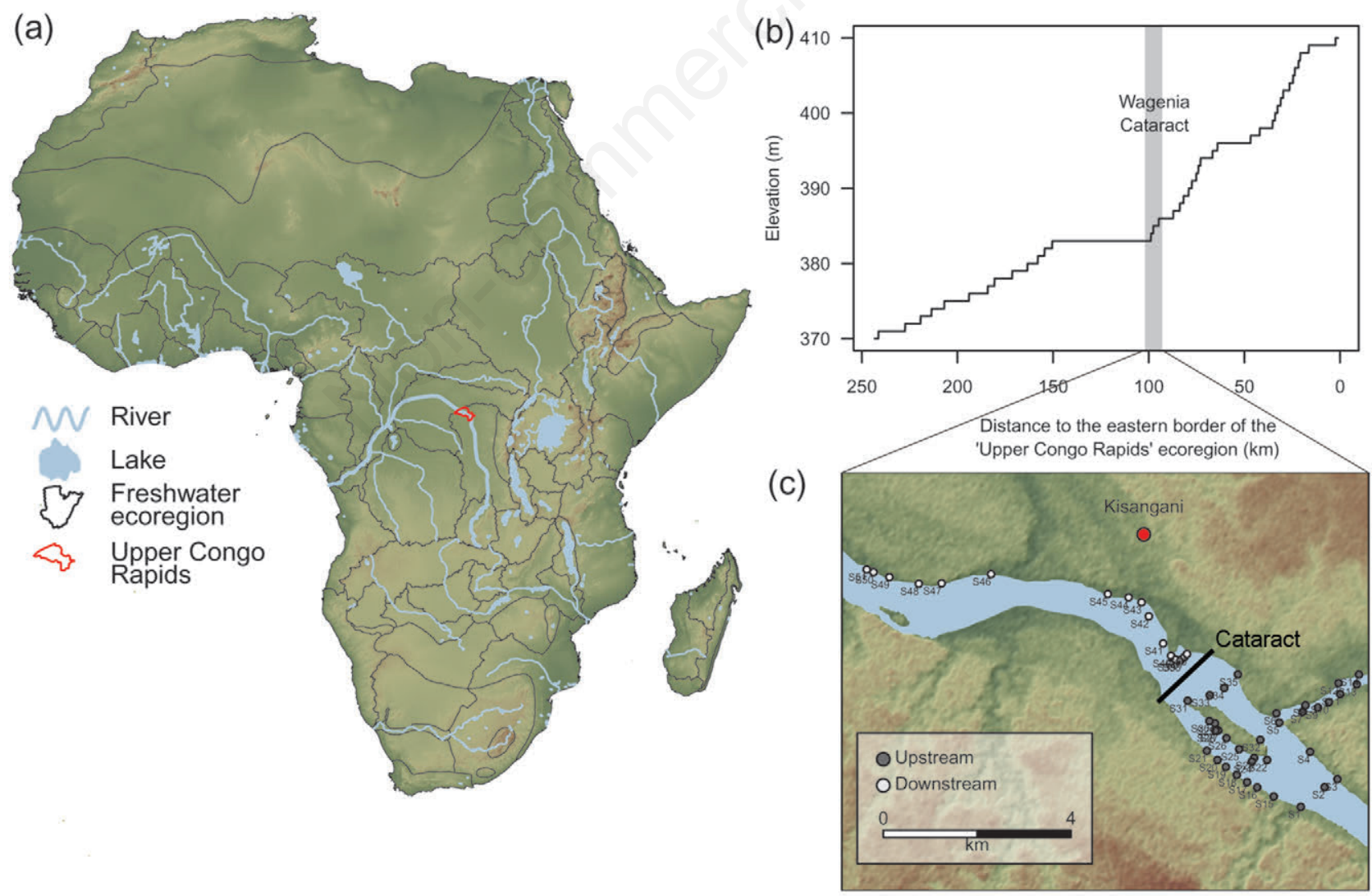

Fig. 1. Study area. Plot showing (a) topographic map with superimposed African freshwater ecoregions (Abell et al., 2008) and the position of the 'Upper Congo Rapids' ecoregion, (b) the elevation of the westwards flowing Congo River along the 'Upper Congo Rapids' ecoregion as extracted from the Shuttle Radar Topographic Mission (Farr et al., 2007), and (c) the 51 sampling localities at the Wagenia Cataract. 
border between the 'Upper Congo' and the 'Cuvette Centrale' ecoregions (Abell et al., 2008). However, considerable uncertainty still exists concerning: i) the universal importance of this barrier across different taxa, and ii) the drivers of biotic differentiation across the barrier (i.e., dispersal filter versus distinct shift in environmental conditions).

Although the Congo River basin is arguably a global hotspot of aquatic biodiversity (Abell et al., 2008; Van Damme and Van Bocxlaer, 2009; Tisseuil et al., 2013), it remains poorly explored. Especially knowledge on its macrozoobenthic invertebrate compositions, such as freshwater mollusks, is only fragmentary. Schultheiß et al. (2011) mentioned that the Congo River basin has been infrequently surveyed for mollusks since the review of Pilsbry and Bequaert (1927). According to Graf et al. (2011), the vast area of Central Africa is basically known only from old collections and from a small number of specimens. Virtually no field surveys have been done for decades (Schultheiß et al., 2011). This is particularly true considering the Wagenia Cataract. Historically the Wagenia Cataract and adjacent stretches of the river are known to be significant in terms of regional freshwater mollusk biodiversity and endemism (Brown, 1994). This includes regionally restricted subspecies but also true endemics (Pilsbry and Bequaert, 1927). None of the historical surveys related mollusk diversity and distribution to the differential barrier- and environmental-effects of the cataracts and the potential downstream directed species dispersal. We here report on the freshwater mollusk species of the Wagenia Cataract and test whether: i) the cataract functions as a dispersal barrier or allows free interchange of freshwater mollusks, ii) local environmental factors correlate with freshwater mollusk community composition, or iii) these communities are better explained by a combined influence of the dispersal barrier, downstream-directed dispersal, and environmental conditions. Moreover, we discuss the biodiversity found and conservation aspects.

\section{METHODS}

\section{Study area}

We conducted the study at the Wagenia Cataract of the Congo River at the town of Kisangani (formerly Stanleyville; $373 \mathrm{~m}$ asl) in the central part of the Democratic Republic of Congo. A series of rapids with an average drop of $1.5 \mathrm{~m}$ constitutes the Wagenia Cataract (Fig. 1). The section of the Congo River investigated stretched over approximately $11 \mathrm{~km}$. It included the main stem of the Congo River, riverbank sites, island sites, and the sidearm of the river upstream of the Wagenia Cataract (Fig. 1c).

\section{Species sampling and identification}

We sampled in 51 sites, 35 upstream and 16 downstream of the Wagenia Cataract (Fig. 1c), with a maximum depth of $4 \mathrm{~m}$ and a distance of $11 \mathrm{~km}$, following Cummings et al. (2016). We chose sites to represent all types of habitats and substrates but could only collect during comparatively low water level. Sampling was carried out from early January to the end of June 2014 covering the rainy and the short dry seasons, with a two weeks sampling rhythm, thus avoiding potential seasonal effects.

Sampling was executed using a scoop net with a diameter of $20 \mathrm{~cm}$ and mesh size of $1 \mathrm{~mm}$. We used a dredge in areas of soft bottom sediments in deeper water and collected by hand picking on the rocky, shallow substrates. Additionally, stones, smaller rocks, and macrophytes were removed from the river and visually searched for mollusks. Sampling effort was constant for $60 \mathrm{~min}$ by two researchers. We recorded geographic coordinates using a hand-held GPS Garmin etrex 20 device. The collected mollusks were transferred into $80 \%$ ethanol and stored in the Hydrobiological and Aquaculture Laboratory of the University of Kisangani.

Mollusks were determined up to species level in most cases, using the nomenclature of Pilsbry and Bequaert (1927), Mandahl-Barth (1988), Brown (1994), and Daget (1998). Given the current level of knowledge of the taxonomic state of many species concerned and the absence of modern taxonomic treatments of virtually all genera involved, we decided to follow this conservative approach here.

\section{Predictors of community turnover}

We generated five different sets of predictors in order to test their influence on community composition: i) environmental factors, ii) the potential cataract barrier, iii) variables for non-directional spatial autocorrelation in community turnover, caused by either unmeasured environmental factors or by biotic processes such as demography and dispersal of species, iv) spatial proxies for downstream-directed spread of chemical water parameters or species dispersal, and v) spatial proxies for the effect of the cataract on downstream communities. For the first set ('Environment'), we measured collection depth with a metered stick. The type of substrate at each locality was determined by presence or absence of nine substrate categories. These substrate categories were set up according to relevance for mollusk species. Substrate type and quality as well as depth are known to be major factors influencing community structure, dispersion, and abundances of macroinvertebrate assemblages (Allan and Castillo, 2007). We utilized the rank-ordered parameter depth and the binary coded type of substrate (Supplementary Tab. 1) of each sampling locality as predictor. The second set tested for differences in community composition 
according to a binary coded upstream/downstream grouping ('Barrier').

The third set of predictors ('Non-directional spatial') consisted of 'distance-based Moran's Eigenvector Maps' (dbMEMs; Borcard et al., 2004) as proxies for spatial autocorrelation in community turnover. dbMEMs are a series of sine waves with decreasing period that model spatial autocorrelation on increasingly smaller scale. We generated 28 dbMEMs by calculating the pairwise watercourse distances (Dijkstra, 1959) between the sampling localities along the watercourse because they represent spatial processes better than Euclidian ('overland') distances. We used the gdistance 1.1-9 (van Etten, 2015) and vegan 2.4-2 (Oksanen et al., 2017) packages for the statistical software R 3.3.2 (R Core Team, 2016) to construct our dbMEMs.

The fourth set of predictors ('Downstream-directed spatial') includes 'Asymmetric Eigenvector Maps' (AEMs; Blanchet et al., 2008b). AEMs are a special form of dbMEM and we used them to model directional spatial processes structuring mollusk community composition. We created a downstream-directed asymmetric connectivity matrix between sampling locations with the mollusk communities 'S1'-'S3' and 'S14' (Fig. 1c) linked to two separated imaginary origins respectively, that is, they are not connected to any sampled upstream community (Fig. S1; Supplementary File). We weighted the link between sampling locations in the connectivity matrix according to weight $=1-\mathrm{d} / \mathrm{d}_{\max }$, with $\mathrm{d}$ being the distance along the watercourse between sampling locations (see above) and constructed the AEMs according to Borcard et al. (2011).

The fifth set of predictors ('Homogenizing cataract') uses the same connectivity matrix than the one above but weights the connection between two localities as weight $=1-\mathrm{N} / \mathrm{N}_{\text {total }}$ (Liu et al., 2013), being $\mathrm{N}$ the number of barriers upstream (in our case one or zero), and $\mathrm{N}_{\text {total }}$ the total number of barriers (in our case one). We used these predictors to test for a similar community composition among sampling localities downstream of the cataract and a downstream-directed spatial community structure of the upstream section. This corresponds to a scenario of biotic homogenization downstream of the cataract (i.e., an indirect influence).

\section{Statistical analysis of community composition}

Because of the variety of necessary sampling methods, we utilized presence/absence data to calculate pairwise Jaccard distances among the mollusk communities using the vegan package. We tested the influence of the individual variables of our five sets of predictors on community composition by subjecting the Jaccard-distance matrix to five individual distance-based redundancy analyses (dbRDA; Legendre and Anderson, 1999; McArdle and Anderson, 2001) using the $d b r d a$ function of the vegan package for R. A preliminary analysis indicated high distances (i.e., high beta-diversity) because of the low share of species between sampling locations. We used the extended step-across strategy (De'ath, 1999), implemented in the vegan package, with a connection limit of 0.95 distance units to prevent the information loss due to high beta-diversity (Smith, 2017). The db-RDA approach constrains ordination axes by ordering the sampling sites along environmental or spatial predictors. We selected the predictors by forward selection through the double stop criterion (Blanchet et al., 2008a) using the vegan package. First, each predictor needs to show significance $(\alpha<0.05)$ after 9999 permutations. Second, the selection of predictors stops if, with additional predictors, the ordination equivalent of the coefficient of determination $\left(\mathrm{R}_{\text {adjusted }}^{2}\right.$, which penalizes additional predictors, does not increase the $\mathrm{R}_{\text {adjusted }}$ any further. We assessed the differential contribution of all significant sets of predictors on community composition, indicated by the $\mathrm{R}_{\text {adjusted, }}$, by subjecting the identified significant predictors to variation partitioning analysis (Peres-Neto et al., 2006). Variation partitioning identifies common and unique contributions of sets of predictors to model community composition. Unique contributions are the fractions of the variance in community composition that can be only explained by one set of predictors. Co-correlated predictors result in shared contributions of their predictor set in explaining variance in community composition, for instance a dbMEM reflecting a spatially structured environmental factor. We performed the variation partitioning analysis using the db-RDA implementation of the varpart function in vegan for $\mathrm{R}$ utilizing the Jaccard-distance measure. We assessed the significance of each testable fraction of predictors by 9999 permutations (Peres-Neto et al., 2006). A fully reproducible report of all analyses is available as Supplementary File.

\section{RESULTS}

\section{Faunal composition}

Sampling of mollusks at the 51 collection points resulted in a total of 1061 specimens, belonging to 19 species or subspecies level taxa, nine genera, eight families, five orders, and two classes (Fig. S2; Supplementary File). Among the 19 taxa, two occurred exclusively upstream, two downstream of the Wagenia Cataract, and 15 were common in both sides (Fig. S2; Supplementary File).

\section{Predictors of mollusk community composition}

Our db-RDA analysis of environmental conditions ('Environmental' db-RDA) using the Jaccard-distance measure showed that substrate features, such as rocks and sand, explained $\mathrm{R}_{\text {adjusted }}^{2}=0.056$ of the mollusk community 
composition (Fig. 2; Tab. 1). With $\mathrm{P}=0.284$ needed to be included in the first step of the forward selection of predictors, the factor 'Barrier' demonstrated no significant differences between communities located up- and downstream of the actual cataract. For the third set of predictors, i.e. non-directional spatial proxies, the db-RDA revealed also no significant predictors. With an $\mathrm{R}_{\text {adjusted }}^{2}=0.177$ (Tab. 1), the six significant proxies for downstream-directed spatial processes (Fig. S3; Supplementary File) explained more variance in mollusk community composition than the environmental factors. In the last individual db-RDA, the four selected proxies modeling homogenous community composition among sampling localities downstream of the cataract and downstream-directed spatial community structure of the upstream section (Fig. 3) explained $\mathrm{R}_{\text {adjusted }}^{2}=0.129$ of the variance in mollusk communities (Tab. 1).

Our variation partitioning analysis confirmed this principal order in explained variance by the individual predictor sets (Fig. 4). However, only the two largest individual fractions (i.e., 'Downstream-directed spatial' and 'Homogenizing cataract') do indeed significantly explain a unique share of variation in community composition. The low and insignificant individual fraction $\left(\mathrm{R}_{\text {adjusted }}^{2}=0.027, \mathrm{P}=0.027\right)$ of the environmental predictors and the higher overlap with the other two sets of predictors $\left(\Sigma \mathrm{R}_{\text {adjusted }}^{2}=0.038\right)$ in explaining variance of community composition (Fig. 4) demonstrated that environmental factors and some spatial proxies could substitute each other (i.e., co-correlation between them). Also the overlap between the 'Downstreamdirected spatial' and the 'Homogenizing cataract' fraction

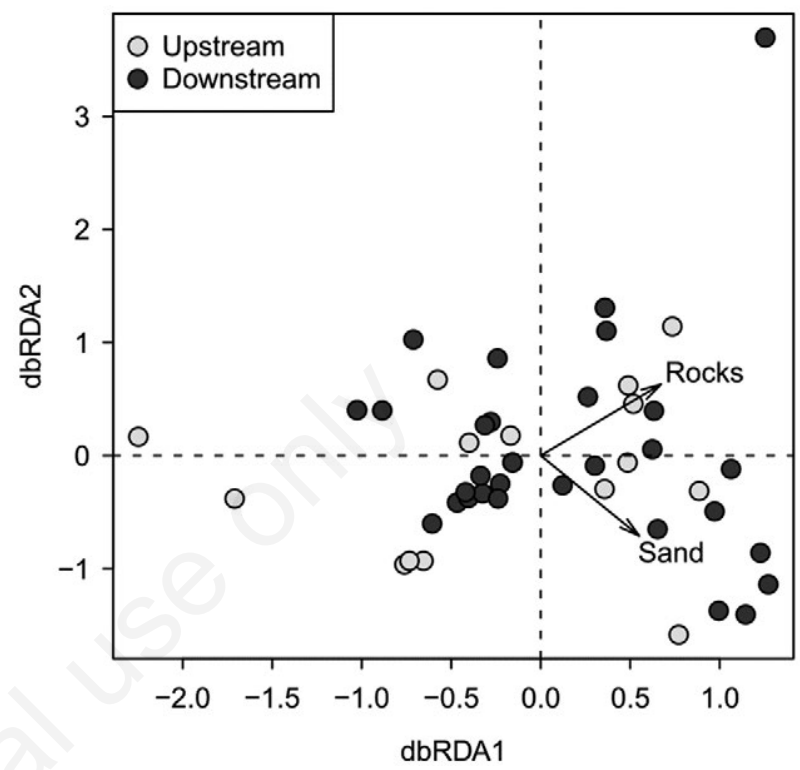

Fig. 2. Biplot of the distance-based redundancy analysis (dbRDA) portraying the correlation of the mollusk community composition with significant environmental predictors and the insignificant cataract-barrier (see also Tab. 1).

Tab. 1. Results of distance-based redundancy analyses (db-RDA) with three different sets of predictors that affected significantly mollusk community composition. First, a db-RDA that includes environmental conditions as predictors. Second, a db-RDA using spatial proxies for downstream-directed processes (AEM) such as the spread of chemical water parameters or species dispersal. Third, spatial proxies for the homogenizing effect of the cataract.

\begin{tabular}{|c|c|c|c|c|}
\hline db-RDA & Predictor & df & F & $\mathbf{R}_{\text {adjusted }}^{2}$ \\
\hline \multirow[t]{3}{*}{ Environment } & & & & 0.056 \\
\hline & Rocks & 1 & $2.63^{*}$ & 0.026 \\
\hline & Sand & 1 & $2.72 *$ & 0.021 \\
\hline \multirow[t]{7}{*}{ Downstream-directed spatial } & & & & 0.177 \\
\hline & AEM1 & 1 & $2.40^{*}$ & 0.021 \\
\hline & AEM3 & 1 & $2.41^{*}$ & 0.020 \\
\hline & AEM5 & 1 & $3.36 * *$ & 0.045 \\
\hline & AEM6 & 1 & $2.34 *$ & 0.021 \\
\hline & AEM13 & 1 & $2.58^{*}$ & 0.028 \\
\hline & AEM15 & 1 & $2.37^{*}$ & 0.023 \\
\hline \multirow[t]{5}{*}{ Homogenizing cataract } & & & & 0.129 \\
\hline & AEM4 & 1 & $3.45 * *$ & 0.047 \\
\hline & AEM6 & 1 & $2.60^{*}$ & 0.029 \\
\hline & AEM10 & 1 & $2.48^{*}$ & 0.021 \\
\hline & AEM11 & 1 & $2.32 *$ & 0.025 \\
\hline
\end{tabular}

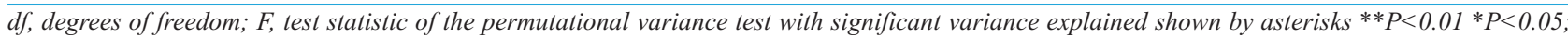
$R_{\text {adiusted }}^{2}$ explained variation in community. 
$\left(\mathrm{R}_{\text {adjusted }}^{2}=0.043\right.$, Fig. 4) indicated that some of their AEMs are co-correlated and thus explain the same share of variance in community composition. However, with a total of $\mathrm{R}_{\text {adjusted }}^{2}=0.292$, a large fraction of variance among mollusk communities remained unexplained.

\section{DISCUSSION}

Ecological settings change along the more than $4000 \mathrm{~km}$ course of the Congo, resulting in its subdivision into several freshwater ecoregions (Abell et al., 2008). In addition to the gradient of environmental conditions along the river continuum, rapids, falls, and cataracts may act as dispersal barriers (Rahel, 2007; Schwarzer et al., 2011). Our study revealed a low but significant effect of substrate type on community composition but no direct influence of the Wagenia Cataract itself. In contrast, we found a stronger indirect effect of this barrier through replacing spatially structured communities upstream of the cataract with more uniform ones downstream.

\section{Barrier function}

Our mollusk survey showed an exclusive upstream/downstream distribution for just four out of 19 species (Fig. S2; Supplementary File), suggesting a limited effect of the cataract acting as a barrier. Moreover, analyzing predictors of community composition evidenced no direct effect of the cataract barrier itself, i.e. no differentiation in distinct up- and downstream communities. However, the AEMs of our fifth set of predictors ('Homogenizing cataract') were specifically designed to test for an indirect effect of the cataract by modeling a similar community composition among sampling localities downstream of the cataract and a downstream-directed spatial community structure of the upstream section. The respective significant individual fraction ('Homogenizing cataract') of our variation partitioning analysis (Fig. 4) shows an indirect imprint of the cataract through replacing spatially structured communities with more uniform ones downstream of the cataract. However, this is not a complete biotic homogenization. The explained variation in community composition was relatively low and the individual fraction of the downstream-directed spatial processes was significant, suggesting an additional spatial structure in community composition imposed over the whole study area.

The Wagenia Cataract has been proposed several times as natural barrier for freshwater fish assemblages (discussed in Decru et al., 2016), though its effect depends on species traits. For example, Danadu et al. (2013) demonstrated that the Wagenia Cataract is a natural barrier for small size Synodontis species but not for larger species. In a similar system in the Madeira River, a tributary of Amazon, Torrente-Vilara et al. (2011) mentioned that the Teotônio Falls potentially impede species flow depending on the capacity of fish to swim faster than the water velocity. It should be emphasized that the effect of barriers is both scale- and taxon-dependent and comparisons should therefore be made carefully. Contrarily to fish species, mollusks not adapted to a rapid habitat can be easily washed downstream but cannot disperse upstream as fast as fish. If active upstream dispersal would be a major factor contributing to the relative 'uniformity' of communities on both sides of the cataracts, one would expect presence of similar species in the actual cataracts. However, freshwater mollusks living directly within the Wagenia Cataract are typically small and reside attached to different substrates (OWN, personal observation). Active upstream mobility for snails ranges between 0.3 to $1.0 \mathrm{~km}$ per year and below $0.1 \mathrm{~km}$ per year for bivalves (Kappes and Haase, 2012). Hence, passive dispersal mechanisms such as river capture or animal vectors, as in other freshwater mollusks (Strong et al., 2008), may play a role in the current distribution of the taxa observed upand downstream of the cataract. The observed indirect effect of the barrier that leads to comparatively more uniform community structure downstream of the cataract might be due to biological drivers. These could potentially be the presence of specialized predators or parasites that
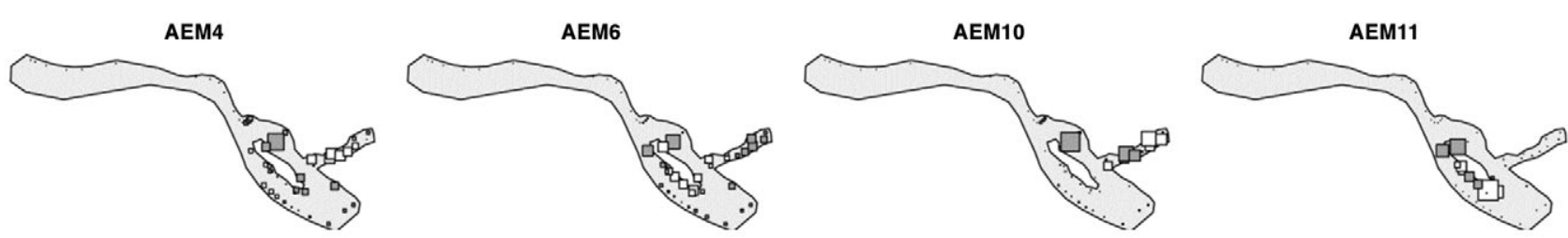

Fig. 3. Plot showing the four significant Asymmetric Eigenvector Maps (AEMs) modeling the homogenizing effect of the Wagenia Cataract. Similar square size and equal color indicates similar mollusk community composition. Higher suffix numbers of the AEMs represent increasingly smaller spatial scale predictions. Note that the sampling locations downstream of the cataract have the same square size and color and therefore approximate a homogeneous community composition. In contrast, the values of the AEMs differ among upstream locations, showing a spatial structure in mollusk community composition. 
are absent or less prominent upstream of the barrier. Likewise, the cataract could create more uniform habitat conditions or river dynamics that in turn are causing the homogenization effect visible. It is therefore important to pay attention to potential environmental drivers shaping mollusk communities up- and downstream of a barrier.

\section{Environmental drivers}

Our results showed that local environmental factors, especially those related to substrate characteristics such as rocks and sand, were significantly correlated with mollusk community composition, but the explained variation was low (Tab. 1). We found a low and insignificant individual fraction of environmental drivers and a high overlap with the AEMs in our partitioning of explained community variation (Fig. 4). This suggests a spatial distribution of substrate features that is somehow similar to the shape of the generated spatial proxies (Fig. 4; Fig. S3; Supplementary File) and therefore both explained the same share of variation in community composition. Such an induced spatial dependency of environmental variables (Legendre et al., 2002) and the co-correlation with spatial proxies is the norm and should be interpreted as environmental control on community composition (Sharma et al., 2011). A high overlap between environmental drivers and the AEMs might also be caused by a potentially easier selection of these spatial predictors and a subsequent overestimation of their explanatory power (Gilbert and

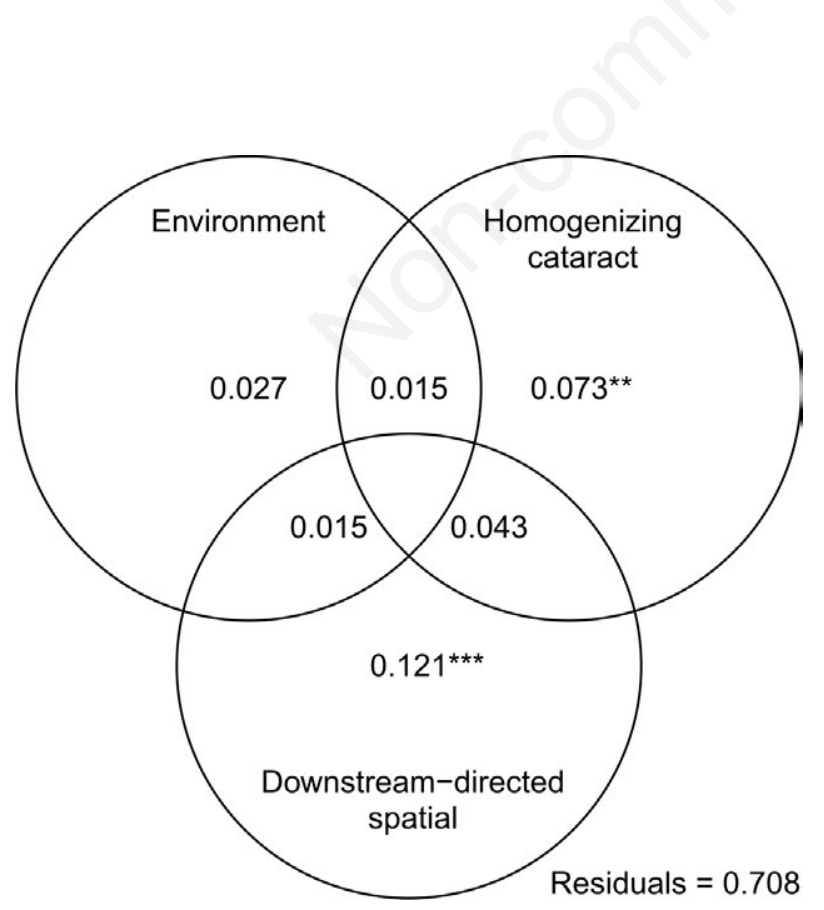

Fig. 4. Venn diagram showing the individual (non-intersecting areas) and common (intersecting areas) fractions of variation in mollusk community composition explained by our three significant sets of predictors. ${ }^{* * *} \mathrm{P}<0.0001 ; * * \mathrm{P}<0.01$.
Bennet, 2010). However, our results confirm expectations, as the substrate is known to influence the benthic assemblages found in fluviatile environments (Allan and Castillo, 2007; Wronski et al., 2015). Abundance and species richness have been demonstrated to correlate with size and heterogeneity of the substrates (Mackay, 1992).

Living in the Congo River requires some degree of adaptation towards rheophilous life-styles. Hard bedrock (i.e., substrate rocks) develops pools and boulder, which represent microhabitats for certain gastropod species (Brown, 1994). These types of substrate structure were also assumed to account for relatively high local biodiversity of mollusks at Wagenia Cataract (Pilsbry and Bequaert, 1927), reconfirmed by our study (see above). In addition, substrate structure might not be the sole factor driving community composition. Future studies should therefore include other potential environmental factors relevant for mollusks.

Factors in all lotic systems that have been shown to determine species assemblages and community structure in invertebrates are the permanent and seasonally higher danger of dislodgement and downstream drift, also known as continuous and catastrophic drift (Wetzel, 2001). This is also true for mollusks (Dillon, 2000). It might therefore be a component explaining the variance observed in our mollusk assemblages.

\section{Downstream dispersal structuring communities}

Out of our five sets of predictors, the spatial proxies for downstream-directed processes explain the highest fraction of variation in mollusk community composition (Tab. 1). Typically, these spatial proxies are interpreted as a sign of directional species dispersal (Sharma et al., 2011; Liu et al., 2013), although the downstream spread of any, for instance, unmeasured chemical water characteristic could also result in the induced spatial autocorrelation of community composition quantified by these spatial proxies (Blanchet et al., 2008b). We think unmeasured downstream-spreading water features are not resulting in a major environmental gradient over the study's spatial extent of $11 \mathrm{~km}$. Therefore, the fraction of explained variation in community composition indeed reflects the importance of downstream-directed dispersal of mollusks. Several studies demonstrated the general importance of downstream-directed species dispersal on determining macroinvertebrate communities (Gray and Arnott, 2011; Funk et al., 2013; Zhang et al., 2014; Curry and Baird, 2015). However, the relative importance of dispersal versus local environmental factors differs among studies. Some authors found higher predictive power of local environmental factors (Zhang et al., 2014), whereas others found prevailing importance of dispersal over environment (Castillo-Escrivà et al., 2016). Liu et al. (2013) suggested that in river benthic diatoms this relative im- 
portance of dispersal decreases if species are attached strongly to the substrate. Mollusks are often living on hard substrates but the strong water current in our study area might reduce this tendency and result in a comparatively higher importance of downstream-directed dispersal than local environmental factors in determining community composition. However, the combination of organismal differences and different spatial scales might also contribute to the disparity in importance of dispersal versus local environmental factors (Gilbert and Bennet, 2010).

\section{Combined influence of environment, dispersal, and the indirect barriers effect}

Our variation partitioning analysis showed that environmental predictors and the two sets of spatial proxies for downstream-directed dispersal and the indirect barrier effect explained community composition largely independently, thus evidencing a combined influence (Fig. 4). The individual fractions of community variation, explained by the two latter sets of predictors, were both significant, meaning they capture features of the mollusk communities not explained by the environmental predictors. The individual fraction of the environmental predictors, however, was not significant, most likely because of induced spatial dependence (see above). In such a case, the overlap with the remaining predictor sets testifies the unique importance of the environment (Sharma et al., 2011), whereas the importance of the spatial proxies is indicated by the size and significance of their unique fractions for explaining variation in community composition.

Comparing the indirect effect of the cataract on mollusk community composition with the effect of environmental factors, we found that these act to a greater extent than the barrier itself (Tab. 1). This comparison needs to be interpreted with caution because under some conditions the explanatory power of spatial variables such as our AEMs might be overestimated (Gilbert and Bennet, 2010). Torrente-Vilara et al. (2011) showed that waterfalls have greater effects than seasonal variations of water level on fish assemblage structure, whereas in diatoms the relative influence of environment versus barrier differed among seasons (Liu et al., 2013). On the stream/river scale, indirect effects of artificial barriers such as dams have been extensively studied and turned out to be profound by disintegrating whole ecosystems (Greathouse $e t$ al., 2006; Kennedy et al., 2016). Few studies exist that examine mollusk communities explicitly, this is especially true for regional or supraregional scales. On continental scale, Hauffe et al. (2014) demonstrated that environmental factors predicted richness of African mollusks better than major barriers of the drainage systems.

Apart from the fact that mollusk community compositions could be related to differences in local environmental factors, an indirect barrier effect, and downstream-directed dispersal, a high proportion of community variation remained unexplained (Fig. 4). Though this is not the only case (Curry and Baird, 2015; Beracko et al., 2016), the source of the uncertainty in community composition needs to be evaluated. We can most likely exclude any spatially structured unmeasured environmental factor. Non-directional spatial predictors (i.e., dbMEMs) capture the effect of environmental induced spatial dependence of community turnover (Sharma et al., 2011) but we did not find a single significant dbMEM. Other reasons for the unexplained fraction of community turnover could be competition between species for limited resources or colonization stochasticity. The latter is a common phenomenon and flood plain dynamics might (re-)shape species communities constantly (Funk et al., 2013; Fernandes et al., 2014). As colonization and recolonization are always linked to species drift in a fluviatile system (Heino et al., 2015), changing source populations might play a role too. The comparatively high proportion of unexplained community turnover in our study might therefore be no exceptional case.

\section{General biodiversity and conservation aspects}

The here revealed presence of 19 molluscan taxa around the Wagenia Cataract cannot easily be compared to the 31 forms listed for the neighborhood of Kisangani by Pilsbry and Bequaert (1927), simply because of a different taxonomic concept used at that time. However, it is noteworthy that some of the endemic elements explicitly mentioned by the latter authors were present also in our study, namely the various forms of Potadoma species, Melanoides wagenia Pilsbry \& Bequaert, 1927 and Lanistes nsendweensis (Dupuis \& Putzeys, 1901). Nevertheless, we also detected some temporal species turnover. For example, Pilsbry and Bequaert (1927) mentioned a Corbicula species as the only bivalve from the Wagenia Cataract, whereas we found five different species but not Corbicula. In contrast to our study, Bulinus as intermediate hosts for schistosomiasis was not found in 1970 close to the Wagenia Cataracts (Frandsen et al., 1978). The growth of the town of Kisangani has ever increased and the environmental impact by human activities is high (Graf et al., 2011; Verhaert et al., 2013), which might have led to changes in the overall faunal composition of the area. This human component has recently been shown to play a role in the introduction of the species Melanoides cf. tuberculata in the Kisangani area unraveled by molecular phylogenetic study (Van Bocxlaer et al., 2015). Such phylogenetic and phylogeographic studies are only beginning to involve mollusks from the Congo River (Schultheiß et al., 2014; Elderkin et al., 2016).

Rapids, falls, and cataracts have been shown to harbor important, especially endemic, biodiversity worldwide. At the same time, they are among the most threatened 
ecosystem as, for example, a demand for hydroelectrical power is drastically increasing (Winemiller et al., 2016; Gregoric and de Lucía, 2016). Our recent survey at the Wagenia Cataract thus reiterates the importance of the 'Upper Congo Rapids' ecoregion as an outstanding hotspot of freshwater mollusk biodiversity, alongside other examples such as the 'Lower Congo Rapids' or 'Malebo Pool' (Graf et al., 2011). Dedicated conservation strategies should be established in the near future to ensure long-term survival of the unique mollusk fauna of the Central Congo River.

\section{CONCLUSIONS}

Our study revealed that the Wagenia Cataract represents no strict dispersal barrier for the interchange of freshwater mollusks. Instead, local environmental factors correlate stronger with freshwater mollusk community compositions, but the mollusk communities on both sides of the cataracts are best explained by a combined effect of the cataract, which homogenizes downstream communities, downstream-directed dispersal, and environmental conditions. Future studies should focus on the homogenizing effect of the cataract by performing a genetic assessment at population level. The presence of some endemic and potentially endangered species has been confirmed for the first time after decades. A permanent monitoring system could allow better assessments of the impacts of temporal fluctuations and stochasticity in community turnover and the conservation status of endemic species at the Wagenia Cataract.

\section{ACKNOWLEDGMENTS}

We thank Victor Kangela and Alain Bolonga for field assistance. OWN is grateful to the Volkswagen Foundation for their generous support that allowed a research internship at JLU Giessen and supports ongoing research in the Central Congo region (VW89358-Muvundja). We would like to thank an anonymous reviewer for helpful comments on earlier versions of the manuscript. The establishment of collaboration between Department of Hydrobiology and Aquaculture, University of Kisangani and the Department of Animal Ecology and Systematics, Justus Liebig University Giessen was supported by a grant to CA (AL 1076/8-1).

\section{REFERENCES}

Abell R, Thieme ML, Revenga C, Bryer M, Kottelat M, Bogutskaya N, Coad B, Mandrak N, Balderas SC, Bussing W, Stiassny MLJ, Skelton P, Allen GR, Unmack P, Naseka A, Ng R, Sindorf N, Robertson J, Armijo E, Higgins JV, Heibel TJ,
Wikramanayake E, Olson D, López HL, Reis RE, Lundberg JG, Sabaj Pérez MH, Petry P, 2008. Freshwater ecoregions of the world: a new map of biogeographic units for freshwater biodiversity conservation. BioScience 58:403-414.

Allan JD, Castillo MM, 2007. Stream ecology: structure and function of running waters. Springer, Dordrecht, The Netherlands: 444 pp.

Barkia H, Barkia A, Yacoubi R, Guamri YE, Tahiri M, Kharrim KE, Belghyti D, 2014. Distribution of fresh-water mollusks of the Gharb area (Morocco). Environments 1:4-13.

Beadle L, 1981. The inland waters of tropical Africa. An introduction to tropical limnology. Longman, London/New York: $475 \mathrm{pp}$.

Beracko P, Matečný I, Košel V, 2016. Long-term changes in freshwater molluscan communities in the middle stretch of the Danube River (Slovakia) over a 23-year period. Fundam. Appl. Limnol. Arch. Fr Hydrobiol. 187:263-280.

Blanchet FG, Legendre P, Borcard D, 2008a. Forward selection of explanatory variables. Ecology 89:2623-2632.

Blanchet FG, Legendre P, Borcard D, 2008b. Modelling directional spatial processes in ecological data. Ecol. Model. 215:325-336.

Borcard D, Giller F, Legendre P, 2011. Numerical ecology with R. Springer, New York: 320 pp.

Borcard D, Legendre P, Avois-Jacquet C, Tuomisto H, 2004. Dissecting the spatial structure of ecological data at multiple scales. Ecology 85:1826-1832.

Brown DS, 1994. Freshwater snails of Africa and their medical importance. Taylor \& Francis, London: 687 pp.

Castillo-Escrivà A, Rueda J, Zamora L, Hernández R, Moral M del, Mesquita-Joanes F, 2016. The role of watercourse versus overland dispersal and niche effects on ostracod distribution in Mediterranean streams (eastern Iberian Peninsula). Acta Oecologica 73:1-9.

Cummings KS, Jones HA, Lopes-Lima M, 2016. Rapid bioassessment methods for freshwater molluscs, p. 185-207. In: T.H. Larsen (ed.), Core standardized methods for rapid biological field assessment. Conservation International, Arlington, VA.

Curry CJ, Baird DJ, 2015. Habitat type and dispersal ability influence spatial structuring of larval Odonata and Trichoptera assemblages. Freshw. Biol. 60:2142-2155.

Daget J, 1998. [Catalogue raisonné des mollusques bivalves d'eau douce africains].[Book in French]. IRD Editions, Leiden/Paris: 340 pp.

Danadu C, Vreven E, Moelants T, Ulyel A-P, Snoeks J, 2013. Two case studies on Synodontis Cuvier, 1816 (Siluriformes: Mochokidae) from the Congo Basin (DRC). Fifth International Conference of the Pan African Fish and Fisheries Association location. Conference Abstracts.

De'ath G, 1999. Extended dissimilarity: a method of robust estimation of ecological distances from high beta diversity data. Plant Ecol. 144:191-199.

Decru E, Moelants T, De Gelas K, Vreven E, Verheyen E, Snoeks J, 2016. Taxonomic challenges in freshwater fishes: a mismatch between morphology and DNA barcoding in fish of the north-eastern part of the Congo basin. Mol. Ecol. Res. 16:342-352.

Dias MS, Oberdorff T, Hugueny B, Leprieur F, Jézéquel C, Cornu J-F, Brosse S, Grenouillet G, Tedesco PA, 2014. 
Global imprint of historical connectivity on freshwater fish biodiversity. Ecol. Lett. 17:1130-1140.

Dijkstra EW, 1959. A note on two problems in connexion with graphs. Numerische Mathematik 1:269-271.

Dillon RT, 2000. The ecology of freshwater molluscs. Cambridge University Press, Cambridge \& New York: 523 pp.

Elderkin CL, Clewing C, Wembo Ndeo O, Albrecht C, 2016. Molecular phylogeny and DNA barcoding confirm cryptic species in the African freshwater oyster Etheria elliptica Lamarck, 1807 (Bivalvia: Etheriidae). Biol. J. Linn. Soc. 118:369-381.

Farr TG, Rosen PA, Caro E, Crippen R, Duren R, Hensley S, Kobrick M, Paller M, Rodriguez E, Roth L, Seal D, Shaffer S, Shimada J, Umland J, Werner M, Oskin M, Burbank D, Alsdorf D, 2007. The Shuttle Radar Topography Mission. Rev. Geophys. 45:1-33.

Fernandes IM, Henriques-Silva R, Penha J, Zuanon J, PeresNeto PR, 2014. Spatiotemporal dynamics in a seasonal metacommunity structure is predictable: the case of floodplain-fish communities. Ecography 37:464-475.

Frandsen F, Bennike T, Cridland CC, 1978. Studies on Schistosoma intercalatum Fisher, 1934 and its intermediate snail host in the Kisangani area, Zaire. Ann. Société Belge Médecine Trop. 58:21-31.

Funk A, Schiemer F, Reckendorfer W, 2013. Metacommunity structure of aquatic gastropods in a river floodplain: the role of niche breadth and drift propensity. Freshwater Biol. 58:2505-2516.

Gilbert B, Bennet JR, 2010. Partitioning variation in ecological communities: do the numbers add up? J. Appl. Ecol. 47:10171082 .

Graf D, Jørgensen A, Van Damme D, Kristensen TK, 2011. The status and distribution of freshwater molluscs (Mollusca), p. 48-61. In: E.G.E. Brooks, D.J. Allen and W.R.T. Darwell (eds.), The status and distribution of freshwater biodiversity in Central Africa. Cambridge, UK and Gland, Switzerland: IUCN.

Gray DK, Arnott SE, 2011. Does dispersal limitation impact the recovery of zooplankton communities damaged by a regional stressor? Ecol. Appl. 21:1241-1256.

Greathouse EA, Pringle CM, McDowell WH, Holmquist JG, 2006. Indirect upstream effects of dams: consequences of migratory consumer extirpation in Puerto Rico. Ecol. Appl. 16:339-352.

Gregoric DEG, de Lucía M, 2016. Freshwater gastropods diversity hotspots: three new species from the Uruguay River (South America). PeerJ. 4:e2138.

Hauffe T, Schultheiß R, Van Bocxlaer B, Prömmel K, Albrecht $\mathrm{C}, 2014$. Environmental heterogeneity predicts species richness of freshwater mollusks in sub-Saharan Africa. Int. J. Earth Sci. 105:1795-1810.

Heino J, Melo AS, Siqueira T, Soininen J, Valanko S, Bini LM, 2015. Metacommunity organisation, spatial extent and dispersal in aquatic systems: patterns, processes and prospects. Freshwater Biol. 60:845-869.

Hynes HBN, 2001. The ecology of running waters. The Blackburn Press, New Jersey: 555pp.

Kappes H, Haase P, 2012. Slow, but steady: dispersal of freshwater molluscs. Aquat. Sci. 74:1-14.

Kennedy TA, Muehlbauer JD, Yackulic CB, Lytle DA, Miller
SW, Dibble KL, Kortenhoeven EW, Metcalfe AN, Baxter $\mathrm{CV}, 2016$. Flow management for hydropower extirpates aquatic insects, undermining river food webs. BioScience 66:561-575.

Legendre P, Anderson MJ, 1999. Distance-based redundancy analysis: Testing multispecies responses in multifactorial ecological experiments. Ecol. Monogr. 69:1-24.

Legendre P, Dale MRT, Fortin MJ, Gurevitch J, Hohn M, Myers $\mathrm{D}, 2002$. The consequences of spatial structure for the design and analysis of ecological field surveys. Ecography 25:601615.

Liu J, Soininen J, Han B-P, Declerck SAJ, 2013. Effects of connectivity, dispersal directionality and functional traits on the metacommunity structure of river benthic diatoms. J. Biogeogr. 40:2238-2248.

Mackay RJ, 1992. Colonization by lotic macroinvertebrates: a review of processes and patterns. Can. J. Fish. Aquat. Sci. 49:617-628.

Mandahl-Barth G, 1988. Studies on African freshwater bivalves. Danish Bilharziasis Laboratory, Charlottenlund, Denmark: $161 \mathrm{pp}$.

Maqboul A, Aoujdad R, Fadli M, Fekhaoui M, 2014. Semiquantitative analysis of freshwater molluscs in the permanent Annasser lakes, Ouergha watershed (Morocco). Int. J. Fauna Biol. Stud. 6:108-113.

McArdle BH, Anderson MJ, 2001. Fitting multivariate models to community data: a comment on distance-based redundancy analysis. Ecology 82:290-297.

Oksanen J, Blanchet FG, Kindt R, Legendre P, Minchin PR, O'Hara RB, Simpson GL, Solymos P, Stevens MHH, Wagner H, 2017. vegan: community ecology package. Available from: https://cran.r-project.org/package=vegan

Peres-Neto PR, Legendre P, Dray S, Borcard D, 2006. Variation partitioning of species data matrixes: estimation and comparison of fractions. Ecology 87:2614-2625.

Pilsbry HA, Bequaert JC, 1927. The aquatic mollusks of the Belgian Congo. With a geographical and ecological account of Congo malacology. Bull. Am. Mus. Nat. Hist. 53:70-658.

Poll M, 1963. [Zoogéographie ichthyologique du cours supérieur du Lualaba].[Article in French]. Publ. Univ. Elisabethville 6:95-106.

R Core Team, 2016. R: A Language and Environment for Statistical Computing. Vienna, Austria.

Rahel FJ, 2007. Biogeographic barriers, connectivity and homogenization of freshwater faunas: it's a small world after all. Freshwater Biol. 52:696-710.

Reckendorfer W, Baranyi C, Funk A, Schiemer F, 2006. Floodplain restoration by reinforcing hydrological connectivity: expected effects on aquatic mollusc communities. J. App. Ecol. 43:474-484.

Runge J, 2008. The Congo River, Central Africa, p. 293-309. In: A. Chupta (ed.). Large rivers: geomorphology and management. J. Wiley \& Sons, Chichester.

Schultheiß R, Van Bocxlaer B, Riedel F, Rintelen T von, Albrecht C, 2014. Disjunct distributions of freshwater snails testify to a central role of the Congo system in shaping biogeographical patterns in Africa. BMC Evol. Biol. $14: 42$.

Schultheiß R, Ndeo OW, Malikwisha M, Marek C, Bößneck U, 
Albrecht C, 2011. Freshwater molluscs of the Eastern Congo: notes on taxonomy, biogeography and conservation. Afr. Invertebr. 52:265-284.

Schwarzer J, Misof B, Ifuta SN, Schliewen UK, 2011. Time and origin of cichlid colonization of the Lower Congo Rapids. PloS One 6:e22380.

Sharma S, Legendre P, De Cáceres M, Boisclair D, 2011. The role of environmental and spatial processes in structuring native and non-native fish communities across thousands of lakes. Ecography 34:762-771.

Smith RJ, 2017. Solutions for loss of information in high-betadiversity community data. Methods Ecol. Evol. 8:68-74.

Strong EE, Gargominy O, Ponder WF, Bouchet P, 2008. Global diversity of gastropods (Gastropoda; Mollusca) in freshwater. Hydrobiologia 595:149-166.

Tischendorf L, Fahrig L, 2000. On the usage and measurement of landscape connectivity. Oikos 90:7-19.

Tisseuil C, Cornu J-F, Beauchard O, Brosse S, Darwall W, Holland R, Hugueny B, Tedesco PA, Oberdorff T, 2013. Global diversity patterns and cross-taxa convergence in freshwater systems. J. Anim. Ecol. 82:365-376.

Torrente-Vilara G, Zuanon J, Leprieur F, Oberdorff T, Tedesco PA, 2011. Effects of natural rapids and waterfalls on fish assemblage structure in the Madeira River (Amazon Basin). Ecol. Freshw. Fish. 20:588-597.

Van Bocxlaer B, Clewing C, Etimosundja J-PM, Kankonda A, Ndeo OW, Albrecht C, 2015. Recurrent camouflaged inva- sions and dispersal of an Asian freshwater gastropod in tropical Africa. BMC Evol. Biol. 15:1-18.

Van Damme D, Van Bocxlaer B, 2009. Freshwater molluscs of the Nile Basin, past and present, p. 585-629. In: The Nile. Springer, Dordrecht.

van Etten J, 2015. gdistance: distances and routes on geographical grids. Available from: https://cran.r-project.org/package= gdistance

Verhaert V, Covaci A, Bouillon S, Abrantes K, Musibono D, Bervoets L, Verheyen E, Blust R, 2013. Baseline levels and trophic transfer of persistent organic pollutants in sediments and biota from the Congo River Basin (DR Congo). Environ. Int. 59:290-302.

Wetzel RG, 2001. Limnology: lake and river ecosystems. Academic Press, San Diego: 1023 pp.

Winemiller KO, McIntyre PB, Castello L, Fluet-Chouinard E, Giarrizzo T, Nam S, Stiassny, MLJ, 2016. Balancing hydropower and biodiversity in the Amazon, Congo, and Mekong. Science 351:128-129.

Wronski T, Dusabe MC, Apio A, Hausdorf B, Albrecht C, 2015. Biological assessment of water quality and biodiversity in Rwandan rivers draining into Lake Kivu. Aquat. Ecol. 49:309-320.

Zhang Y, Zhang J, Wang L, Lu D, Cai D, Wang B, 2014. Influences of dispersal and local environmental factors on stream macroinvertebrate communities in Qinjiang River, Guangxi, China. Aquat. Biol. 20:185-194. 